\title{
Opioids for breathlessness: a narrative review
}

\author{
Miriam J Johnson (D) , ${ }^{1}$ David C. Currow (D) 1,2
}

${ }^{1}$ Wolfson Palliative Care

Research Centre, University of Hull, Hull, UK

${ }^{2}$ IMPACCT, Faculty of Heath, University of Technology Sydney, Sydney, New South Wales, Australia

\section{Correspondence to}

Professor Miriam J Johnson, Wolfson Palliative Care Research Centre, University of Hull, Hull HU6 7RX, Kingston upon Hull, UK; miriam.johnson@hyms.ac.uk

Received 20 March 2020

Revised 25 May 2020

Accepted 3 June 2020

Published Online First

3 July 2020

\section{Check for updates}

(c) Author(s) (or their employer(s)) 2020. No commercial re-use. See rights and permissions. Published by BMJ.

To cite: Johnson MJ, Currow DC. BMJ Supportive \& Palliative Care 2020;10:287-295.

\section{ABSTRACT}

Chronic breathlessness is a disabling and distressing condition for which there is a growing evidence base for a range of interventions. Nonpharmacological interventions are the mainstay of management and should be optimised prior to use of opioid medication. Opioids are being implemented variably in practice for chronic breathlessness. This narrative review summarises the evidence defining current opioids for breathlessness best practice and identifies remaining research gaps. There is level 1a evidence to support the use of opioids for breathlessness. The best evidence is for 10-30 mg daily de novo low-dose oral sustainedrelease morphine in opioid-naïve patients. This should be considered the current standard of care following independent, regulatory scrutiny by one of the world's therapeutics regulatory bodies. Optimal benefits are seen in steady state; however, there are few published data about longer term benefits or harms. Morphine-related adverse events are common but mostly mild and self-limiting on withdrawal of drug. Early and meticulous management of constipation, nausea and vomiting is needed particularly in the first week of administration. Serious adverse events are no more common than placebo in clinical studies. Observational studies in severe chronic lung disease do not show excess mortality or hospital admission in those taking opioids. We have no long-term data on immune or endocrine function. There are promising data regarding prophylaxis for exertion-related breathlessness, but given the risks associated with transmucosal fentanyl, caution is needed with regard to clinical use pending longer term, robust safety data.

\section{BACKGROUND}

Chronic breathlessness is a pivotal symptom in three ways. First, chronic breathlessness is an important signpost to underlying pathology, although often misattributed as 'benign' (deconditioning, ageing, obesity) $)^{12}$ or inevitable ('I've smoked for many years') by the person with it or, if identified in a clinical consultation, by their clinician. Second, it is the cause of a disabling syndrome of chronic breathlessness which persists despite optimised treatment of underlying pathology ${ }^{3}$ and which affects every aspect of the person's life and the lives of those who care for them. ${ }^{4}$ Third, changes in chronic breathlessness are a useful way to monitor the effectiveness of treatments of underlying pathologies. ${ }^{5}$ Exertionlimiting breathlessness affects nearly 1 in 10 of the general population ${ }^{6}$ and is associated with poorer quality of life for each successive drop in the level of exertion that can be achieved before breathlessness limits exercise, ${ }^{7}$ psychological morbidity (anxiety, depression and both) ${ }^{8}$ and increased health service utilisation. ${ }^{910}$

The evidence base supporting interventions to modulate the generation and/ or perception of breathlessness itself is growing. Recent delineation of a chronic breathlessness syndrome ${ }^{3}$ (disabling breathlessness which persists despite optimal treatment of the underlying pathophysiology) underlines the importance of both optimised disease-treatments and the need for breathlessness-directed interventions. The evidence emphasises the importance of a diagnostic workup to look at disease-modifying therapies, and concomitant non-pharmacological interventions for breathlessness for managing chronic breathlessness. The evidence is also growing for additional pharmacological interventions, aiming to reduce the subjective sensation of breathlessness. In particular, the use of morphine is being implemented variably into clinical practice, and a sustained release preparation of oral morphine (Kapanol) has had its license extended to include for the first time in the world an indication for the pharmacological treatment of chronic breathlessness. ${ }^{11}$ The Therapeutics Goods Administration in Australia, as the national medication regulatory agency, independently reviewed data in order to make this decision. 
This narrative review presents the current knowledge about the use of opioids in chronic breathlessness and highlights areas for further research.

\section{Basic science of opioids and breathlessness} Opioid receptors

There is good rationale to use opioids. Perceptions associated with breathlessness are processed in the insula, dorsal anterior cingulate cortex, amygdala and medial thalamus; areas shared with processing the perceptions of pain and other 'threats', ${ }^{12}$ and richly innervated with opioid receptors. ${ }^{13}$

Much early laboratory work studied the effect of opioids on exercise tolerance rather than symptomatic benefits for people with chronic breathlessness. ${ }^{14} 15$ Most studies were single-dose studies, thus limiting conclusions regarding the symptomatic benefit possible with steady state. More recent laboratory tests of the symptom impact of opioids showed that endogenous opioids reduce breathlessness; naloxone increased the perceived work of breathlessness in people with moderate-to-severe chronic obstructive pulmonary disease (COPD) for a given workload. ${ }^{14} 15$

Endogenous opioids are thought to centrally modulate breathlessness perception to be less intense and unpleasant. A study of people with COPD given ketoconazole to cause increased beta-endorphins was randomly given placebo or naloxone. ${ }^{16}$ Those given naloxone did not gain the reduction in breathlessness seen in the placebo arm. However, Currow et al did not replicate these findings in a 3 -arm cross-over trial of peripheral blockade (methylnaltrexone), peripheral and central blockade (naltrexone) or no blockade (placebo); there was no statistically significant difference in the primary outcome of breathlessness intensity. ${ }^{17}$ In addition, in general, nebulised opioid studies have not shown benefit ${ }^{18}$ other than one study in a specific population of people with COPD exposed to mustard gas ${ }^{19}$ and a recent crossover randomised controlled trial (RCT) of 11 people with COPD showed a statistically and clinically (reduction in breathlessness intensity of $\geq 1$ point on a 0 to 10 numerical rating scale (NRS) $)^{20}$ significant effect. ${ }^{21}$ However, systematic absorption of opioid was not measured in either study thus a central mechanism cannot be excluded.

The role of individual opioid receptors is not clear. The effect on mu opioid receptors appears clear from clinical and laboratory studies of morphine, fentanyl and remifentanil. What is less clear is the effect of the semisynthetic opioid, oxycodone on symptomatic breathlessness. Its action is shared between agonist effects on mu and kappa receptors. To date, the two largest placebo controlled clinical trials of oxycodone have failed to demonstrate any signal (early evidence of benefit; the point estimate is in favour of the intervention but may not reach statistical significance) of net symptomatic benefit on chronic breathlessness. ${ }^{22} 23$
Neuroimaging and breathlessness perception

Much of our understanding about breathlessness perception comes from neuroimaging studies, mainly functional magnetic resonance imaging (fMRI). Pattinson et al demonstrated in 2009 that remifentanil reduced the sensation, 'urge to breath' and highlighted breathlessness due to disease as a potential therapeutic target for opioids. ${ }^{24}$ Since then, our understanding of how the brain responds to repeated breathlessness stimuli has deepened. Based on previous experience, the brain appears to create expectations and beliefs (psychological 'priors') which then influence the perception of incoming breathlessness sensations.$^{25}$ Thus, people living with chronic breathlessness process the sensation of breathlessness involving the frontal association cortex, in the context of memory and fear associated with past experiences. Healthy volunteers do not. ${ }^{26}$ Importantly, interventions such as pulmonary rehabilitation, which aim to educate and change such beliefs, also show corresponding reduction in fMRI frontal association cortex activity. ${ }^{27}$ Interestingly, administration of opioid appears to reduce anticipatory breathlessness. In an fMRI study of healthy volunteers, administration of remifentanil not only depressed activity in breathlessness pathways during breathlessness, but also depressed anticipatory activity in the amygdala and the hippocampus that correlated with reductions in breathlessness unpleasantness. ${ }^{28}$

In addition to the influence of prior expectations, affective states such as anxiety and depression appear to amplify perception of breathlessness. The role of any impaired affect in reducing opioid effectiveness in pain has been previously described ${ }^{29}$ along with an association with escalating doses and difficulties in dose reduction, but recently has been shown to similarly reduce opioid effectiveness in breathlessness. Abdallah et al recently demonstrated that in both people with chronic breathlessness (using morphine) and healthy volunteers (remifentanil), even subtle reductions in measures of mood reduced breathlessness response to opioids: as depression and anxiety increased, so opioid responsiveness decreased. ${ }^{30}$ This has important clinical implications. People with significant depression and/or anxiety should therefore first be managed with nonpharm psychoeducational approaches to modify the impact of emotion on opioid responsiveness before using opioids in order to maximise opioid response and reduce the risk of adverse effects due to inappropriate dose escalation.

Interindividual variation in response to exogenous opioid It is apparent that not everyone's breathlessness responds to opioid. ${ }^{3132}$ A large cross-sectional pharmacogenetics study ${ }^{33}$, people taking morphine were three times more likely to have more intense breathlessness if they had a single nucleotide polymorphism (SNP) on the HTR3B gene. No relationship with candidate single nucleotide polymorphisms tested was identified 
Box 1 Summary basic science: opioids and breathlessness

- Endogenous opioids modify perception of breathlessness.

- Evidence for a central modulation is the dominant evidence in the literature.

- Opioids reduce the sensation 'urge to breathe' through cortical mechanisms.

- The response to opioids is reduced by impaired affect (anxiety, depression).

- Opioids appear to be able to modulate anticipatory breathlessness as well as the sensation of breathlessness itself.

- There is interindividual breathlessness response to opioids due to varying affective state and pharmacogenetics.

for people taking oxycodone or fentanyl. This biologically plausible SNP (associated with opioid receptors) warrants further investigation and is awaiting confirmation in other prospective studies.

Box 1 summarises the key messages.

\section{Clinical studies: effectiveness, dosing and safety} Effectiveness

Most participants in clinical trials to date have been in people with COPD and the majority of people randomised in placebo-controlled, double-blind studies have been treated with once daily, sustained release morphine in the active arm. A sizeable number of people with cancer and heart failure have been included, but few with interstitial lung disease (ILD) or other conditions that also cause chronic breathlessness.

Meta-analyses of randomised placebo-controlled trials have studied the evidence base for the use of opioids for breathlessness. The first (2002) found moderate evidence to support a symptomatic benefit in reducing breathlessness for systemic opioids but not for nebulised opioids. ${ }^{34}$ A subsequent second systematic review (2014) of only people with COPD demonstrated moderate level evidence that morphine in this setting is effective and safe. ${ }^{35}$ The benefit was most marked in people in steady state with a standardised mean difference of -0.44 (95\% CI -0.68 to -0.19$)$ compared with $-0.30(95 \% \mathrm{CI}-0.59$ to -0.02$)$ for all studies. Such a difference translates into a difference in breathlessness score beyond the minimum clinically important difference for reduction in breathlessness. ${ }^{20}$ These data challenge the widespread practice using small doses of immediate release morphine at widely spaced dosing intervals for up to several weeks before considering a change to sustained release preparations. This delays achievement of steady state and fits with neither the pharmacokinetic nor pharmacodynamics effects of morphine for the symptomatic reduction of chronic breathlessness. It is also consistent with the potential reduction in anticipatory breathlessness afforded by opioid discussed earlier (neuroimaging and breathlessness perception); having persistent levels of opioid around the clock may modulate the central response with regard to expectation.$^{28}$

As discussed above, in general, nebulised opioid studies have not shown benefit ${ }^{18}$ other than one study in a specific population of people with COPD exposed to mustard gas ${ }^{19}$ and a recent cross-over RCT of 11 people with COPD showed a clinically and statistically significant effect. ${ }^{21}$ However, systematic absorption of opioid was not measured in either study; thus, a central mechanism cannot be excluded.

A third systematic review and meta-analysis in $2016^{36}$ found a smaller effect with lower precision. However, they did not account for the cross-over design of all except one of the studies, used a fixed rather than random-effect model despite study heterogeneity and used a sample size of $<50$ (irrespective of statistical power or cross-over design) as a marker of low-quality evidence. A subsequent meta-analysis of the same papers which addressed these methodological concerns ${ }^{18}$ found an increased effect size and improved precision-a moderate level evidence of benefit of a magnitude consistent with the known clinical important difference (distribution and patient anchor) of 1 point on a $0-10$ NRS scale. ${ }^{20}$

Since this last review, the largest to date phase III clinical trial of 7 days oral low-dose sustained release morphine and placebo for chronic breathlessness due to various conditions has reported. ${ }^{37}$ This study was larger than the population even in the most recent review. ${ }^{18}$ There was no benefit for the primary outcome of breathlessness now over placebo but methodological issues ${ }^{38}$ make interpretation difficult:

i. Due to slow recruitment, eligibility criteria were expanded to include people with less severe breathlessness. As people with more severe breathlessness are more likely to respond to morphine, ${ }^{32}$ and are those in whom morphine is clinically indicated, ${ }^{32} 39$ this may have reduced the power of the trial to detect benefit in those in whom it would be used clinically.

ii. There was no measure of physical activity and so morphine-related improvement of exercise tolerance would have been undetected in those who continued exercising until stopped by the same worst intensity of breathlessness.

iii. Immediate release morphine was available in both arms with greater use in the placebo arm.

Therefore, previous level 1a (meta-analysis) evidence, and basic science data should not be discarded in the light of this trial. Weawait results from soon to report subsequent studies which restrict eligibility to more severe breathlessness, do not allow 'as needed' immediate release morphine and include measures of physical activity to help interpret changes in breathlessness severity (see later section 'Ongoing, or still-to-bereported clinical trials').

A further trial of regular, low-dose, oral sustainedrelease morphine for heart failure-related breathlessness has also been reported. ${ }^{40}$ The trial was closed early 
due to difficulties in recruitment, but showed greater within arm improvements in the morphine arm than placebo for all breathlessness measures except average breathlessness. This trial provides the first reported longer term placebo-controlled data.

Breathlessness due to all diseases may not respond to morphine. A phase II trial recently reported worse outcome in the morphine arm compared with placebo in every symptom measure in people with primary pulmonary hypertension. ${ }^{41}$ Due to the signals of harms, a further phase III trial could not be justified.

As discussed in the first section, placebo-controlled trials so far have failed to show benefit for oxycodone. 2223

Trials of opioids and exertional breathlessness

As physical exertion generates breathlessness, central 'blunting' of breathlessness perception may allow more physical exertion. If so, this could have clinical implications for both daily activity in people with severe chronic breathlessness and for use with interventions such as pulmonary rehabilitation where breathlessness is a reason for low rates of referral, poor attendance if referred and increased drop-out. ${ }^{42}$ Unfortunately, a phase II trial of opioids during pulmonary rehabilitation did not demonstrate feasibility due to poor recruitment because people with the most severe breathlessness were not referred to pulmonary rehabilitation services. ${ }^{43}$

The Ekström review ${ }^{35}$ failed to demonstrate benefit for exercise capacity. However, although there are no phase III trials of prophylactic opioid administration, there are a number of small pilot/feasibility phase II trials indicating before-after within arm benefit in terms of exercise-induced breathlessness intensity and greater exercise endurance with subcutaneous, ${ }^{44}$ transnasal, ${ }^{45}$ buccal, ${ }^{46}$ or nebulised fentanyl ${ }^{47}$ although none was powered for between-arm comparison. More recently, in a dose-finding pilot study, Hui et al randomised 50 opioid-tolerant people with cancer to receive one of two doses of fentanyl sublingual spray or placebo prior to a shuttle walk test. ${ }^{48}$ The higher dose group reported significantly improved breathlessness and walk distance (pre-post analysis) compared with placebo. The lower dose group had significantly improved walk distances and a non-significant improvement in breathlessness. In addition, Abdallah et al randomised 20 adults with advanced COPD and chronic breathlessness syndrome to receive oral immediate release morphine or placebo prior to constant-load cardiopulmonary cycle exercise testing. ${ }^{42}$ Those receiving morphine had better exercise endurance (increased exercise endurance time by $2.5 \pm 0.9 \mathrm{~min} ; \mathrm{p} \leq 0.014)$ and reduced exertional breathlessness at isotime $(1.2 \pm 0.4$ Borg units; $\mathrm{p} \leq 0.014)$.

However, despite the promise of these early trials, it must be emphasised that there are very few long-term data on use of transmucosal fentanyl for breathlessness. The only published data relate to a case report of abuse of transmucosal fentanyl for breathlessness (a patient with COPD who had been prescribed up to 4 doses of $50 \mu \mathrm{g}$ daily for the past 3 years, who presented using 40 doses each day) with withdrawal during rationalisation of regimen. ${ }^{49}$ The misuse potential of transmucosal fentanyl should be systematically investigated prospectively before this approach is used routine in clinical practice.

\section{Ongoing, or still-to-be-reported clinical trials}

All but one reported randomised study to date has a short follow-up (4-7 days at most). There are currently three ongoing or imminently reporting phase III trials in people with chronic breathlessness, all of which have longer follow-up. The Morphine for Treatment of Dyspnea in Patients With COPD (MORDYC) trial has completed recruitment and used $20 \mathrm{mg}$ daily modified release morphine in a 3-month, parallel group, placebocontrolled trial in people with COPD with health-related quality of life as the primary outcome. ${ }^{50}$ (NCT02429050) The Breathlessness, Exertion And Morphine Sulphate (BEAMS) trial has also completed recruitment and is a placebo-controlled dose titration, three arm trial of regular, low dose, sustained release oral morphine $(0 \mathrm{mg}, 8 \mathrm{mg} 16 \mathrm{mg})$ in people with COPD. ${ }^{51}$ This study includes a blinded extension from the primary end point for up to 6 months for each participant. A third phase III placebo-controlled RCT using a dose increase step from $10 \mathrm{mg}$ to $20 \mathrm{mg}$ oral modified release morphine daily depending on breathlessness response is in startup. (ISRCTN87329095) These studies will also help address the current unknowns regarding longer term use.

Two placebo-controlled, randomised studies: $5 \mathrm{mg}$ of immediate release morphine four times daily (NCT02622022) or once daily sustained release morphine $20 \mathrm{mg}$ (ACTRN12611000711910) in people with ILD are soon due to report or complete, respectively. It will be interesting to see whether there is a symptomatic response achieved or whether the outcomes are more akin to the pulmonary artery hypertension study.

Box 2 summarises the key messages.

Dosing and dose titration

A phase II dose ranging study was conducted with a lower dose daily capsule of extended release morphine. ${ }^{31}$ People were commenced on $10 \mathrm{mg}$ daily for a week and if they had a response (predefined as $>10 \%$ reduction over baseline breathlessness), they went to the pharmacovigilance extension phase at that dose. If they received no benefit, the dose was increased to $20 \mathrm{mg}$ for a week and that algorithm was repeated up to $30 \mathrm{mg}$ as necessary. In all, 83 people were enrolled of whom two out of three derived symptomatic benefit. Seventy per cent of those deriving benefit did so at $10 \mathrm{mg} / 24$ hours, $20 \%$ at $20 \mathrm{mg} / 24$ hours and $8 \%$ at $30 \mathrm{mg} / 24$ hours. There were nine people who had no toxicity but had still not experienced a symptomatic benefit at $30 \mathrm{mg}$. Patients were followed for up to 22 months after commencing extended release morphine. Once again, 


\section{Box 2 Summary effectiveness}

- Opioids have moderate level 1a evidence (systematic review and meta-analysis) for effectiveness for breathlessness.

- Most evidence is in people with chronic obstructive pulmonary disease.

- The largest randomised clinical trials use regular, lowdose, sustained release morphine de novo in opioid-naïve participants.

- Opioids are most effective in steady state rather than single-dose studies.

- There is preliminary evidence to support prophylaxis for exertion-induced breathlessness for both morphine and fentanyl but the risk-benefit balance is not known, especially with longer term use.

- Not all disease states may have breathlessness which respond to morphine.

- Not all opioids show reduction in breathlessness

- There are very few placebo-controlled data to date regarding medium or long-term use. Recent trials are due to report soon.

most participants had COPD. Importantly, no tachyphylaxis (benefit was maintained without dose increase) was observed over follow-up.

A secondary analysis of this dose ranging study looked at people who had a successful titration from either $10-20 \mathrm{mg}$ or $20-30 \mathrm{mg} .{ }^{52}$ Those improving on titration experienced a marked improvement in the first 24 hours but that initial benefit continued to increase over the ensuing 6 days without further changes in dose. As such, in people taking extended release morphine, when a symptomatic benefit is achieved, the maximal benefit is several days later; hence, upward titration should not occur within 1 week of upward dose titration.

One study addresses the issue of how opioids for breathlessness should be titrated for people who are already taking opioids for pain. ${ }^{53}$ The randomised, double-blind study showed that people who had a $25 \%$ increase in the opioid dose taken for breakthrough pain derived benefit for breathlessness, but a dose increment of $50 \%$ delivered no more symptomatic benefit than one of $25 \%$. There was no placebo comparator and thus we do not know if the benefit seen was greater than no treatment.

\section{Safety}

Opioids have been used for centuries to relieve pain and other symptoms, and the safety profile is well studied and understood. The risk of respiratory compromise in people with conditions causing breathlessness has led to opioids being (almost absolutely) contraindicated in these patients, but in the clinical studies described above there were no reported cases of respiratory depression or obtundation, despite these problems being actively sought.
Safety has been further measured in a number of ways. A systematic review, including a subgroup meta-analysis of studies measuring changes in oxygenation and carbon dioxide retention, concluded that the doses of systemic opioid used did not affect oxygenation nor worsen carbon dioxide retention in a clinically meaningful way (mean partial pressure of carbon dioxide was $0.27 \mathrm{kPa}$ higher (0.08 to $0.45 \mathrm{kPa}$ higher) in the opioid group; mean partial pressure of oxygen and mean oxygen saturation was $0.26 \mathrm{kPa}$ lower $(0.68$ to $0.15 \mathrm{kPa}$ higher $)$ and $0.47 \%$ lower $(0.87 \%$ to $0.07 \%$ lower), respectively, in the opioid group). ${ }^{54}$ This review included all study designs, including case reports. There was only one report of clinically meaningful respiratory depression described in a single case report of a patient taking regular sustained release morphine for cancer pain who required shortterm respiratory assistance following a nebulised dose of morphine for breathlessness. ${ }^{55}$ Since this review, there have been two further case reports: one in a patient with COPD taking background sustained release morphine and concomitant immediate release morphine presenting with respiratory depression following a large immediate release dose,${ }^{56}$ the other was of the patient with COPD with transmucosal fentanyl discussed above. ${ }^{49}$

The largest longer term studies have been conducted as observational consecutive cohort studies looking at outcomes after opioids are started. At doses of $30 \mathrm{mg}$ of morphine equivalent per 24 hours or less, Ekström's large consecutive COPD and long-term oxygen cohort with 4 years' follow-up showed no increase in hospital admissions nor in mortality when opioids were commenced at a morphine equivalent daily dose of $\leq 30 \mathrm{mg} .{ }^{57} \mathrm{~A}$ subsequent study in people with ILD again showed no excess mortality or hospital admissions in people taking opioids. ${ }^{58}$ Recent publication from a large Canadian population of people with COPD has shown a very small absolute excess respiratory adverse effects over the first 30 days of prescription in those using opioids, ${ }^{59}$ but the data carry the usual challenges of interpretation with regard to defining an association, given unmeasured confounders. In such a study, cause and effect cannot be attributed, and there is no information regarding the clinical circumstances regarding initiation or monitoring of drug. Further, most appear to be given for musculoskeletal pain rather than breathlessness. The authors aimed to reduce confounding due to patients with advanced disease by excluding patients who had a coded palliative care consult. Given the well-recognised very poor referral rates for people with COPD to palliative care, this is unlikely to have been effective in excluding such patients. ${ }^{60}$

Morphine-related harms are well understood. In the morphine/placebo clinical studies where these have been systematically sought and reported, treatmentemergent adverse events (those which appear or worsen compared with baseline (TEAEs)) are mainly mild and are self-limiting on withdrawal of morphine, with no excess serious adverse events in the morphine arm. ${ }^{236162}$ 


\section{Box 3 Summary clinical studies: dose and safety}

Most of those with morphine-responsive breathlessness respond to doses of $\leq 30 \mathrm{mg} / 24$ hours orally.

- Seventy per cent of responders do so by $10 \mathrm{mg} / 24$ hours orally.

- Respiratory adverse effects appear to be minimal especially when using regular, sustained release morphine, and clinically relevant respiratory depression limited to single case reports from suboptimally monitored clinical practice.

- Placebo-controlled trials report no excess serious treatment-emergent adverse events in the morphine arm.

- Morphine-related adverse events are generally mild and include constipation, nausea and vomiting, the latter two of which are mostly self-limiting.

- Morphine-related adverse events in steady state are more likely in people with fluctuating renal function, especially if renal function was reduced in the first place.

The exception was the heart failure trial, where TEAEs were more common in the morphine group, although all except one were mild and were more likely in participants with worse renal function (estimated glomerular filtration $<54 \mathrm{~mL} / \mathrm{min}$, the group's mean value). ${ }^{40}$ Of note, most events occurred in the first week of administration suggesting that dosing is otherwise well tolerated up to 3 months. A recent analysis ${ }^{63}$ of treatment-emergent adverse events in the largest morphine/placebo trial showed only $4 \%$ of potentially morphine-related adverse events in the dataset as a whole were classified as serious. Importantly, there was no statistically significant difference in either non-serious or serious TEAEs between the two groups. However, in a number of the clinical studies, more participants withdrew from study drug in the morphine arm indicating a qualitative difference in experience even if this was not captured quantitatively. ${ }^{4063}$ We do not have safety data beyond 3 months, or data on immune or endocrine function in the longer term. As people with chronic lung and heart conditions may live with chronic breathlessness for some years, we should not initiate morphine for breathlessness in those with only mild or moderate symptom, or in those who have not been optimised with non-pharmacological treatment.

Box 3 summarises the key messages.

\section{What studies are likely to report in the near future?}

Two large studies will report in 2020: one from The Netherlands $^{50}$ and the other from Australia/New Zealand. ${ }^{51}$ Both have been designed explicitly to extend the understanding of the role of controlled/ extended release morphine in the symptomatic reduction of chronic breathlessness. These studies have been conceived given current understanding of the measurement and impact of chronic breathlessness on patients and their caregivers. The studies have complementary outcome measures and, importantly, blinded longer term data to define the net effects for up to 6 months. Measures on quality of life will allow better estimates of health economic impacts. Seeking baseline clinical demographic predictors of response and a pharmacogenetics substudy (the Australasian study) will further our understanding of people most likely to benefit.

\section{Other potential studies}

Cancer-related pain control can be achieved more rapidly and with fewer side-effects in opioid-naïve patients when titrated de novo with controlled release opioids than with immediate release opioid solutions. ${ }^{64}$ This raises the question of whether a head-to-head study using the same design in chronic breathlessness can be justified, although it may be argued that the two paradigms are not necessarily the same. The pharmacokinetics and existing evidence support the use of sustained release morphine where it is available, and where it is not available or affordable, the use of immediate release solution administered regularly to achieve steady state creates a viable alternative.

The symptomatic management of acute-on-chronic breathlessness is a challenge. Non-pharmacological measures such as a hand-held electric fan and psychoeducational interventions are of benefit. Evidence to date suggests that the duration of such episodes, especially if occurring with an obvious precipitant, is brief and no pharmacological agent to date has the combined pharmacokinetic/pharmacodynamic characteristics to provide predictable reduction of acute-on-chronic breathlessness in a timely way and the risk of abuse or harm is considerable.

Preliminary studies of prophylactic transmucosal fentanyl for exertion-induced breathlessness in opioidtolerant people suggest that a phase III placebocontrolled RCT is warranted. However, because of the risk of escalating use for any exertion where other management approaches are safer and as, if not more, effective, the patient population should be carefully defined. This approach should be limited to people with severe functional impairment due to acute-on-chronic breathlessness related to specified activities and when the benefits likely outweigh potential risks. In addition, careful choice of fentanyl preparation is important as they carry different pharmacokinetic profiles ${ }^{65}$ for example, intranasal sprays have a rapid rise and fall profile (time to maximal level (TMax) up to $15 \mathrm{~min}$ ), buccal tablets have a rapid increase with sustained intensity (TMax up to $90 \mathrm{~min}$ ), and oral transmucosal fentanyl citrate has a slow onset and longer duration (TMax up to $120 \mathrm{~min}$ ).

Of note, as most episodes of acute-on-chronic breathlessness take less than half an hour to recover these pharmacokinetic profiles suggest that transmucosal fentanyl has a limited, if any, role in the acute management of acute-on-chronic breathlessness episodes. Given these timeframes, any immediate benefit is likely to be due to psychological mechanisms such as 'doing something' or even cold stimulation of the nasal mucosae. 


\section{CONCLUSIONS}

There is level 1a evidence to support the use of opioids for breathlessness. The best evidence is for low-dose oral sustained release morphine at doses of between 10 $\mathrm{mg}$ and $30 \mathrm{mg}$ daily de novo in opioid-naïve patients, which should be considered the current standard of care following independent, regulatory scrutiny by one of the world's therapeutics regulatory bodies.

Optimal benefits are seen in steady state from regular dosing; however, there are few published data about longer term benefits or harms. However, morphinerelated adverse events are common, mostly mild and self-limiting on withdrawal of drug. Serious adverse events are no more common than placebo in clinical studies. Observational studies in severe COPD and ILD do not show excess mortality or hospital admission in those taking opioids. We do not have long-term data on immune or endocrine function.

There are promising data regarding prophylaxis for exertion-related breathlessness, but given the risks associated with transmucosal fentanyl, caution is needed with regard to clinical use pending longer term, robust safety data.

\section{Twitter Miriam J Johnson @MJJohnson_HYMS}

Contributors Concept and design; revisions for intellectual content; and approval final manuscript: both authors. First draft: MJJ.

Funding The authors have not declared a specific grant for this research from any funding agency in the public, commercial or not-for-profit sectors.

Competing interests DC has received an unrestricted research grant from Mundipharma, is an unpaid member of an advisory board for Helsinn Pharmaceuticals and has consulted Mayne Pharma and received intellectual property payments from them. MJJ has received consulting payments from Mayne Pharma.

Patient consent for publication Not required.

Provenance and peer review Not commissioned; externally peer reviewed.

ORCID iDs

Miriam J Johnson http://orcid.org/0000-0001-6204-9158

David C. Currow http://orcid.org/0000-0003-1988-1250

\section{REFERENCES}

1 Gysels M, Higginson IJ. The experience of breathlessness: the social course of chronic obstructive pulmonary disease. J Pain Symptom Manage 2010;39:555-63.

2 Johnson MJ, Bowden JA, Abernethy AP, et al. To what causes do people attribute their chronic breathlessness? a population survey. J Palliat Med 2012;15:744-50.

3 Johnson MJ, Yorke J, Hansen-Flaschen J, et al. Towards an expert consensus to delineate a clinical syndrome of chronic breathlessness. Eur Respir J 2017;49. doi:10.1183/13993003.02277-2016. [Epub ahead of print: 25 May 2017].

4 Hutchinson A, Barclay-Klingle N, Galvin K, et al. Living with breathlessness: a systematic literature review and qualitative synthesis. Eur Respir J 2018;51. doi:10.1183/13993003.01477-2017. [Epub ahead of print: 21 Feb 2018].
5 Kocks JWH, van den Berg JWK, Kerstjens HAM, et al. Day-to-day measurement of patient-reported outcomes in exacerbations of chronic obstructive pulmonary disease. Int $J$ Chron Obstruct Pulmon Dis 2013;8:273-86.

6 Currow DC, Plummer JL, Crockett A, et al. A community population survey of prevalence and severity of dyspnea in adults. J Pain Symptom Manage 2009;38:533-45.

7 Currow DC, Dal Grande E, Ferreira D, et al. Chronic breathlessness associated with poorer physical and mental health-related quality of life (SF-12) across all adult age groups. Thorax 2017;72:1151-3.

8 Currow DC, Chang S, Reddel HK, et al. Breathlessness, anxiety, depression, and function-the BAD-F study: a crosssectional and population prevalence study in adults. J Pain Symptom Manage 2020;59:197-205.

9 Hutchinson A, Pickering A, Williams P, et al. Breathlessness and presentation to the emergency department: a survey and clinical record review. BMC Pulm Med 2017;17:53.

10 Stevens JP, Dechen T, Schwartzstein R, et al. Prevalence of dyspnea among hospitalized patients at the time of admission. $J$ Pain Symptom Manage 2018;56:15-22.

11 Australian Product Information. Kapanol@ (morphine sulfate pentahydrate) capsules. therapeutic goods administration, Australia, 2019. Available: https://www.ebs.tga.gov.au/ebs/ picmi/picmirepository.nsf/pdf?OpenAgent\&id=CP-2013-PI01928-1\&d=201908211016933 [Accessed 21 Aug 2019].

12 von Leupoldt A, Sommer T, Kegat S, et al. Dyspnea and pain share emotion-related brain network. Neuroimage 2009;48:200-6.

13 Baumgärtner U, Buchholz H-G, Bellosevich A, et al. High opiate receptor binding potential in the human lateral pain system. Neuroimage 2006;30:692-9.

14 Gifford AH, Mahler DA, Waterman LA, et al. Neuromodulatory effect of endogenous opioids on the intensity and unpleasantness of breathlessness during resistive load breathing in COPD. COPD 2011;8:160-6.

15 Mahler DA, Murray JA, Waterman LA, et al. Endogenous opioids modify dyspnoea during treadmill exercise in patients with COPD. Eur Respir J 2009;33:771-7.

16 Mahler DA, Gifford AH, Waterman LA, et al. Effect of increased blood levels of $\beta$-endorphin on perception of breathlessness. Chest 2013;143:1378-85.

17 Currow DC, Hunt T, Louw S, et al. Isolating peripheral effects of endogenous opioids in modulating exertional breathlessness in people with moderate or severe COPD: a randomised controlled trial. ERJ Open Res 2019;5. doi:10.1183/23120541.00153-2019

18 Ekström M, Bajwah S, Bland JM, et al. One evidence base; three stories: do opioids relieve chronic breathlessness? Thorax 2018;73:88-90.

19 Shohrati M, Ghanei M, Harandi AA, et al. Effect of nebulized morphine on dyspnea of mustard gas-exposed patients: a double-blind randomized clinical trial study. Pulm Med 2012;2012:1-6.

20 Johnson MJ, Bland JM, Oxberry SG, et al. Clinically important differences in the intensity of chronic refractory breathlessness. J Pain Symptom Manage 2013;46:957-63.

21 Janowiak P, Krajnik M, Podolec Z, et al. Dosimetrically administered nebulized morphine for breathlessness in very severe chronic obstructive pulmonary disease: a randomized, controlled trial. BMC Pulm Med 2017;17:186.

22 Ferreira DH, Louw S, McCloud P, et al. Controlledrelease oxycodone vs. placebo in the treatment of chronic Breathlessness-A multisite randomized placebo controlled trial. J Pain Symptom Manage 2020;59:581-9.

23 Oxberry SG, Torgerson DJ, Bland JM, et al. Shortterm opioids for breathlessness in stable chronic heart failure: a randomized controlled trial. Eur J Heart Fail 2011;13:1006-12. 
24 Pattinson KTS, Governo RJ, MacIntosh BJ, et al. Opioids depress cortical centers responsible for the volitional control of respiration. J Neurosci 2009;29:8177-86.

25 Faull OK, Hayen A, Pattinson KTS. Breathlessness and the body: neuroimaging clues for the inferential leap. Cortex 2017;95:211-21.

26 Herigstad M, Hayen A, Evans E, et al. Dyspnea-related cues engage the prefrontal cortex: evidence from functional brain imaging in COPD. Chest 2015;148:953-61.

27 Herigstad M, Faull OK, Hayen A, et al. Treating breathlessness via the brain: changes in brain activity over a course of pulmonary rehabilitation. Eur Respir J 2017;50. doi:10.1183/13993003.01029-2017

28 Hayen A, Wanigasekera V, Faull OK, et al. Opioid suppression of conditioned anticipatory brain responses to breathlessness. Neuroimage 2017;150:383-94.

29 Edwards RR, Dolman AJ, Michna E, et al. Changes in pain sensitivity and pain modulation during oral opioid treatment: the impact of negative affect. Pain Med 2016;17:1882-91.

30 Abdallah SJ, Faull OK, Wanigasekera V, et al. Opioids for breathlessness: psychological and neural factors influencing response variability. Eur Respir J 2019;54. doi:10.1183/13993003.00275-2019

31 Currow DC, McDonald C, Oaten S, et al. Once-daily opioids for chronic dyspnea: a dose increment and pharmacovigilance study. J Pain Symptom Manage 2011;42:388-99.

32 Johnson MJ, Bland JM, Oxberry SG, et al. Opioids for chronic refractory breathlessness: patient predictors of beneficial response. Eur Respir J 2013;42:758-66.

33 Currow DC, Quinn S, Ekstrom M, et al. Can variability in the effect of opioids on refractory breathlessness be explained by genetic factors? BMJ Open 2015;5:e006818.

34 Jennings A-L, Davies AN, Higgins JPT, et al. A systematic review of the use of opioids in the management of dyspnoea. Thorax 2002;57:939-44.

35 Ekström M, Nilsson F, Abernethy AA, et al. Effects of opioids on breathlessness and exercise capacity in chronic obstructive pulmonary disease. A systematic review. Ann Am Thorac Soc 2015;12:1079-92.

36 Barnes H, McDonald J, Smallwood N, et al. Opioids for the palliation of refractory breathlessness in adults with advanced disease and terminal illness. Cochrane Database Syst Rev 2016;3:CD011008.

37 Currow D, Louw S, McCloud P, et al. Regular, sustainedrelease morphine for chronic breathlessness: a multicentre, double-blind, randomised, placebo-controlled trial. Thorax 2020;75:50-6.

38 Janssen DJA, Johnson MJ. Palliative treatment of chronic breathlessness syndrome: the need for P5 medicine. Thorax $2020 ; 75: 2-3$.

39 Marciniuk DD, Goodridge D, Hernandez P, et al. Managing dyspnea in patients with advanced chronic obstructive pulmonary disease: a Canadian thoracic Society clinical practice guideline. Can Respir J 2011;18:69-78.

40 Johnson MJ, Cockayne S, Currow DC, et al. Oral modified release morphine for breathlessness in chronic heart failure: a randomized placebo-controlled trial. ESC Heart Fail 2019;6:1149-60.

41 Ferreira DH, Ekström M, Sajkov D, et al. Extended-release morphine for chronic breathlessness in pulmonary arterial hypertension-A randomized, double-blind, placebo-controlled, crossover study. J Pain Symptom Manage 2018;56:483-92.

42 Keating A, Lee A, Holland AE. What prevents people with chronic obstructive pulmonary disease from attending pulmonary rehabilitation? A systematic review. Chron Respir Dis 2011;8:89-99.

43 Kochovska S, Fazekas B, Hensley M, et al. A randomized, double-blind, multisite, pilot, placebo-controlled trial of regular, low-dose morphine on outcomes of pulmonary rehabilitation in COPD. J Pain Symptom Manage 2019;58:e7-9.

44 Hui D, Xu A, Frisbee-Hume S, et al. Effects of prophylactic subcutaneous fentanyl on exercise-induced breakthrough dyspnea in cancer patients: a preliminary double-blind, randomized, controlled trial. J Pain Symptom Manage 2014;47:209-17.

45 Hui D, Kilgore K, Park M, et al. Impact of prophylactic fentanyl pectin nasal spray on exercise-induced episodic dyspnea in cancer patients: a double-blind, randomized controlled trial

46 Hui D, Kilgore K, Frisbee-Hume S, et al. Effect of prophylactic fentanyl buccal tablet on episodic exertional dyspnea: a pilot double-blind randomized controlled trial. J Pain Symptom Manage 2017;54:798-805.

47 Jensen D, Alsuhail A, Viola R, et al. Inhaled fentanyl citrate improves exercise endurance during high-intensity constant work rate cycle exercise in chronic obstructive pulmonary disease. J Pain Symptom Manage 2012;43:706-19.

48 Hui D, Hernandez F, Larsson L, et al. Prophylactic fentanyl sublingual spray for episodic exertional dyspnea in cancer patients: a pilot double-blind randomized controlled trial. $J$ Pain Symptom Manage 2019;58:605-13.

49 Janssen DJA, van den Beuken-van Everdingen MHJ, Verberkt CA, et al. Fentanyl nasal spray in a patient with end-stage COPD and severe chronic breathlessness. Breathe 2019; 15:e122-5.

50 Verberkt CA, van den Beuken-van Everdingen MHJ, Franssen FME, et al. A randomized controlled trial on the benefits and respiratory adverse effects of morphine for refractory dyspnea in patients with COPD: protocol of the MORDYC study. Contemp Clin Trials 2016;47:228-34.

51 Currow D, Watts GJ, Johnson M, et al. A pragmatic, phase III, multisite, double-blind, placebo-controlled, parallel-arm, dose increment randomised trial of regular, low-dose extendedrelease morphine for chronic breathlessness: breathlessness, exertion and morphine sulfate (beams) study protocol. BMJ Open 2017;7:e018100.

52 Currow DC, Quinn S, Greene A, et al. The longitudinal pattern of response when morphine is used to treat chronic refractory dyspnea. J Palliat Med 2013;16:881-6.

53 Allard P, Lamontagne C, Bernard P, et al. How effective are supplementary doses of opioids for dyspnea in terminally ill cancer patients? A randomized continuous sequential clinical trial. J Pain Symptom Manage 1999;17:256-65.

54 Verberkt CA, van den Beuken-van Everdingen MHJ, Schols JMGA, et al. Respiratory adverse effects of opioids for breathlessness: a systematic review and meta-analysis. Eur Respir J 2017;50. doi:10.1183/13993003.01153-2017. [Epub ahead of print: 22 Nov 2017].

55 Lang E, Jedeikin R. Acute respiratory depression as a complication of nebulised morphine. Can J Anaesth 1998;45:60-2.

56 Politis J, Le B, Smallwood N. Respiratory depression secondary to morphine use in a patient with COPD and refractory breathlessness. Eur Respir J 2017;49:1601858.

57 Ekström MP, Bornefalk-Hermansson A, Abernethy AP, et al. Safety of benzodiazepines and opioids in very severe respiratory disease: national prospective study. BMJ 2014;348:g445.

58 Bajwah S, Davies JM, Tanash H, et al. Safety of benzodiazepines and opioids in interstitial lung disease: a national prospective study. Eur Respir J 2018;52. doi:10.1183/13993003.01278-2018. [Epub ahead of print: 06 Dec 2018].

59 Vozoris NT, Wang X, Fischer HD, et al. Incident opioid drug use and adverse respiratory outcomes among older adults with COPD. Eur Respir J 2016;48:683-93. 
60 Currow DC, Ekström M, Johnson MJ. Opioids in chronic obstructive pulmonary disease: the whole picture using all available evidence. $\mathrm{Br}$ J Clin Pharmacol 2016;81:795-6.

61 Abernethy AP, Currow DC, Frith P, et al. Randomised, double blind, placebo controlled crossover trial of sustained release morphine for the management of refractory dyspnoea. BMJ 2003;327:523-8.

62 Currow DC, Ekstrom M, Fazekas B, et al. A phase III, multi-site, randomised, double blind, placebo controlled parallel arm study of daily extended release (ER) morphine for chronic breathlessness. European J Palliative Care $2017 ; 17$.
63 Johnson MJ, Sbizzera I, Fairhurst C, et al. No excess harms from sustained-release morphine: a randomised placebocontrolled trial in chronic breathlessness. BMJ Support Palliat Care 2019; doi: 10.1136/bmjspcare-2019-002009 [Epub ahead of print: 12 Nov 2019].. doi:10.1136/bmjspcare-2019-002009. [Epub ahead of print:

64 Klepstad P, Kaasa S, Jystad A, et al. Immediate- or sustainedrelease morphine for dose finding during start of morphine to cancer patients: a randomized, double-blind trial. Pain 2003;101:193-8.

65 Moore N, Darwish M, Amores X, et al. A review of the pharmacokinetic profile of transmucosal fentanyl formulations. Curr Med Res Opin 2012;28:1781-90. 